\title{
The impact of HIV on the prevalence of asthma in Uganda: a general population survey
}

Bruce J. Kirenga ${ }^{1 *}$ (D), Levicatus Mugenyi ${ }^{2}$, Corina de Jong ${ }^{3,4}$, J. Lucian Davis ${ }^{5}$, Winceslaus Katagira ${ }^{6}$, Thys van der Molen ${ }^{3,4}$, Moses R. Kamya ${ }^{7}$ and Marike Boezen ${ }^{8}$

\begin{abstract}
Background: HIV and asthma are highly prevalent diseases in Africa but few studies have assessed the impact of HIV on asthma prevalence in high HIV burden settings. The objective of this analysis was to compare the prevalence of asthma among persons living with HIV (PLHIV) and those without HIV participating in the Uganda National Asthma Survey (UNAS).

Methods: UNAS was a population-based survey of persons aged $\geq 12$ years. Asthma was diagnosed based on either self-reported current wheeze concurrently or within the prior 12 months; physician diagnosis; or use of asthma medication. HIV was defined based on confidential self-report. We used Poisson regression with robust standard errors to estimate asthma prevalence and the prevalence ratio (PR) for HIV and asthma.

Results: Of 3416 participants, 2067 (60.5\%) knew their HIV status and 103 (5.0\%) were PLHIV. Asthma prevalence was $15.5 \%$ among PLHIV and 9.1\% among those without HIV, PR 1.72, (95\%Cl 1.07-2.75, $p=0.025)$. HIV modified the association of asthma with the following factors, PLHIV vs. not PLHIV: tobacco smoking (12\% vs. $8 \%$, $p=<0.001)$, biomass use (11\% vs. $7 \%, p=<0.001)$, allergy $(17 \%$ vs. $11 \%, p=<0.001)$, family history of asthma (17\% vs. $11 \%, p=<0.001)$, and prior TB treatment (15\% vs. $10 \%, p=<0.001)$.

Conclusion: In Uganda the prevalence of asthma is higher in PLHIV than in those without HIV, and HIV interacts synergistically with other known asthma risk factors. Additional studies should explore the mechanisms underlying these associations. Clinicians should consider asthma as a possible diagnosis in PLHIV presenting with respiratory symptoms.
\end{abstract}

Keywords: Asthma, HIV, Prevalence, Uganda

\section{Background}

Human Immunodeficiency Virus (HIV) and asthma are both highly prevalent diseases globally $[1,2]$. An estimated 334 million people have asthma and 36.7 million people have HIV [1, 2]. Both diseases disproportionately affect Africa and other low and middle income countries (LMICs) [2, 3]. The weighted mean prevalence of asthma in Africa is $7.0 \%$ in the rural areas (2.5-11.5) and 9.6\%

\footnotetext{
* Correspondence: brucekirenga@yahoo.co.uk

${ }^{1}$ Makerere University Lung Institute \& Division of Pulmonary Medicine, Department of Medicine, Makerere University College of Health Sciences, Kampala, Uganda

Full list of author information is available at the end of the article
}

(3.9-15.2) in urban areas. The prevalence of asthma and HIV in Uganda is $10 \%$ and $6.2 \%$ respectively $[4,5]$.

Epidemiological studies have found increased prevalence of asthma among HIV infected persons [6-13]. However, the number of studies is small and most are either clinical or hospital based and most of them have been conducted in high income low HIV burden settings. Examples of available studies include a study that included 248 HIV infected and 236 HIV uninfected males. This study found that the prevalence of wheezing was $54.4 \%$, vs. $21.2 \%, p<0.001$ [9]. In another study among 223 HIV patients in the USA, the prevalence of doctor diagnosed asthma was 20.6 compared to $8.2 \%$ in the general population [13]. In a study comparing 14,005

(C) The Author(s). 2018 Open Access This article is distributed under the terms of the Creative Commons Attribution 4.0 International License (http://creativecommons.org/licenses/by/4.0/), which permits unrestricted use, distribution, and 
HIV infected with age matched HIV uninfected controls in Canada, the prevalence ratio for asthma was 1.31 (95\% CI 1.20-1.43) [12].

Several mechanisms through which HIV increases the prevalence of asthma have been proposed [14-16]. Notable among these is the HIV associated persistent immune activation and inflammation [17]. It is also postulated that HIV proteins such as the nef protein or activation of memory CD4 $\mathrm{T}$ cells directly increase the risk of asthma [18]. Studies indicate that the higher the viral loads, the worse the lung function in HIV infected populations $[14,17]$. HIV infected persons have been found to have higher levels of Immunoglobulin E (IgE) and this increases with increasing immunosuppression [15]. IgE is a well-known mediator of allergy and asthma. HIV could also drive asthma through its association with predominance of T-helper 2 (Th2) pathway. Priming of the Th2 pathway is known to increase the risk of asthma and other allergic diseases [19, 20]. In a cohort of 223 HIV infected persons, doctor diagnosed asthma appeared to be more common in participants with high sputum interleukin 4 (IL-4) (27\% with asthma if high IL-4 vs.10.5\% with asthma if low IL-4, $p=0.02$ ) [13]. Antiretroviral therapy (ART) medications used to treat HIV have also be implicated in increasing the risk of asthma among HIV infected persons [21].

An interaction between HIV and asthma is important in high HIV burden settings because with the availability of highly active antiretroviral therapy and efficient health systems to deliver them, many HIV infected people are living longer into age groups where non-communicable diseases (NCDs) are common. In addition, prevention of HIV may lead to reduction in the burden of asthma. Data on the burden of asthma in HIV may also lead to assessment of asthma in HIV and routine HIV testing among persons with asthma. Drug-drug interactions in the management of patients with asthma-HIV comorbidity is also a key consideration.

In this study we analyzed data from the Uganda national asthma survey (UNAS) to determine if the prevalence of asthma was higher among persons with self-reported HIV infection. We also aimed to determine if HIV interacts with other known asthma risk factors namely tobacco smoking, biomass use, TB, family history of asthma and allergy.

\section{Methods}

\section{Design and study participants}

UNAS was a cross sectional general population-based survey conducted in Uganda in 2016. Participants were selected in clusters (villages) selected by probability proportionate to size by the Uganda Bureau of Statistics using the Uganda National population and housing census of 2014. Households (HHs) within clusters were selected by simple random sampling from a $\mathrm{HH}$ list generated by village leaders. All persons aged $\geq 12$ years who were members of selected $\mathrm{HH}$ and provided written informed consent (and assent in case of minors) were surveyed. Exclusion criteria were: residing in congregate settings (schools, prisons, homes) and temporary residents (less than 2 weeks in household of selected villages).

\section{Asthma diagnosis}

Sampled participants were interviewed by trained research assistants using a standardized questionnaire developed by adapting questions from internationally recognized questionnaires, including the World Health Organization (WHO) health survey $[1,22]$, the international study of asthma and allergies in children (ISAAC) [22] and the European community respiratory health survey (ECRHS) surveys [23]. Asthma was defined as self-report of physician diagnosis, prescribed use of breathing medications for asthma or report of a wheeze in the last 12 months.

\section{HIV diagnosis}

HIV status in this survey was established by self-report. All participants were asked about their HIV status in private interviews. Responses were either HIV positive, HIV negative or unknown HIV status. HIV positive participants were classified as persons living with HIV (PLHIV).

\section{Statistical analysis}

Participants with unknown HIV status were excluded from this analysis. Participants' demographic and social characteristics and known asthma risk factors (tobacco smoking, allergy, family history of asthma, biomass use, and history of TB treatment) were summarized as proportions and compared between PLHIV and those who were not using Chi-square and Fisher's exact test statistics as appropriate.

We used Poisson regression with robust standard errors to estimate asthma prevalence and prevalence ratios (PR) between PLHIV and those who were not [24]. The Poisson model, an alternative for the log-binomial, was used due to convergence problems with the latter approach. The prevalence of asthma and the corresponding PRs among patients with key asthma risk factors namely tobacco smoking, biomass smoke exposure, family history of asthma, tuberculosis (TB) and allergy were also calculated. The PR ratio of asthma between PLHIV and those who were not living with HIV was then finally adjusted for these risk factors. Exposure to biomass smoke was defined as cooking in the living space (same room where participants slept), tobacco smoking was by self-report of being a smoker while allergy was considered to be present if a participant reported suffering in the past 12 months 
from any of the following: suffering in the past 12 months from any of watery itchy eyes, recurrent skin rash, or having sneezing, nasal congestion or rhinorrhea in the absence of an upper respiratory tract infection). To assess for the interaction between HIV and known asthma risk factors (tobacco smoking, biomass use, history of TB treatment, allergy, family history), we calculated age-dependent asthma prevalence comparing PLHIV and those who were not while keeping all other factors at zero and then by each factor. A graphical aid was used to visualize the age-dependent asthma prevalence by these factors.

\section{Results}

\section{Characteristics of study participants}

Of 3416 UNAS participants, 2067 (60.5\%) knew their HIV status and 103 reported to be living with HIV (5.0\% of the group that knew their HIV status). The characteristics of these participants by HIV status are shown in Table 1 . The proportions of participants with respiratory symptoms of cough, sputum production and wheezing did not differ by HIV status. However, the proportions with the symptom breathlessness differed significantly by HIV

Table 1 Participant characteristics Please see my feedback in the previous file

\begin{tabular}{|c|c|c|c|}
\hline & $\begin{array}{l}\text { PLHIV } \\
(N=103)\end{array}$ & $\begin{array}{l}\text { Not PLHIV } \\
(N=1964)\end{array}$ & $P$-value \\
\hline \multicolumn{4}{|l|}{ Characteristic } \\
\hline Male gender, $n(\%)$ & $31(30.1)$ & $763(38.8)$ & 0.076 \\
\hline Age groups $n(\%)$ & & & $<0.001$ \\
\hline$<15$ & $1(1.0)$ & $91(4.6)$ & \\
\hline $15-24$ & $10(9.7)$ & $474(24.1)$ & \\
\hline $25-34$ & $27(26.2)$ & $510(25.9)$ & \\
\hline $35-44$ & $33(32.0)$ & $388(19.7)$ & \\
\hline $45-54$ & $27(26.2)$ & $304(15.5)$ & \\
\hline $55-64$ & $4(3.9)$ & $131(6.7)$ & \\
\hline $65+$ & $1(1.0)$ & $68(3.5)$ & \\
\hline \multicolumn{4}{|l|}{ Respiratory Symptoms $n(\%)$} \\
\hline Cough & $23(22.3)$ & $404(20.6)$ & 0.665 \\
\hline Sputum & $7(6.8)$ & $140(7.1)$ & 0.900 \\
\hline Wheezing & $11(10.7)$ & $131(6.7)$ & 0.116 \\
\hline Shortness of breath & $18(17.5)$ & $177(9.0)$ & 0.004 \\
\hline \multicolumn{4}{|c|}{ Risk factors and co-morbid conditions $n(\%)$} \\
\hline History of smoking & $13(12.6)$ & $155(7.9)$ & 0.086 \\
\hline Exposure to bio-mass & $24(23.3)$ & 385 (19.6) & 0.357 \\
\hline Ever been treated for TB & $10(9.7)$ & $30(1.5)$ & $<0.001$ \\
\hline Allergy & $42(40.8)$ & $721(36.7)$ & 0.400 \\
\hline Family history of asthma & $15(14.6)$ & $220(11.2)$ & 0.295 \\
\hline
\end{tabular}

PLHIV people living with HIV, TB tuberculosis status, positive vs. negative $(17.5 \%$ vs. $9.0 \%, p=0.004)$. Tobacco smoking was higher among PLHIV (12.6\% vs. $7.9 \%, p=0.086)$ as well as having history of TB treatment $(9.7 \%$ vs. $1.5 \%, p<0.001)$.

\section{Prevalence of asthma by HIV status}

The prevalence of asthma among PLHIV was 15.5\% while that among those without HIV was $9.1 \%$, PR 1.72 (95\% CI: $1.07-2.75, p=0.025$ ). After adjusting for gender, age, tobacco smoking, biomass exposure, TB treatment, family history of asthma and allergy, the PR ratio decreased to 1.54 (95\% CI: 0.94-2.51, $p=0.085$ ), Table 2 . A high prevalence of asthma among PLHIV was maintained at all ages irrespective of absence or presence of other risk factors of tobacco smoking, biomass use, allergy, family history of asthma and previous TB treatment (Fig. 1). Considering only participants younger than 35 years the prevalence of asthma was still higher among PLHIV, PR 3.06 (Fig. 2). The prevalence of asthma among participants with known HIV status and unknown HIV status did not differ significantly $(9.4 \%$ vs.9.0\%, $p=0.689$ ), Table 3. HIV modified the association between asthma and other asthma risk factors, positive vs. negative: tobacco smoking ( $12 \%$ vs. $8 \%, p=<$ $0.001)$ biomass use ( $11 \%$ vs. $7 \%, p=<0.001)$, allergy $(17 \%$ vs. $11 \%, p=<0.001)$, family history asthma $(17 \%$ vs. $11 \%, p=<0.001)$ and TB treatment $(15 \%$ vs. $10 \%$, $p=<0.001)$, Fig. 3 .

\section{Prevalence of asthma by other factors}

Other factors associated with increased prevalence of asthma in this study were biomass use adjusted PR 1.56 (95\% CI: $1.18-2.07, p=0.002$ ), tobacco smoking 1.79 (95\% CI: $1.23-2.60, p=0.002$ ), history of TB treatment 2.20 (95\% CI: $1.26-3.84, p=0.005$ ), family history of asthma 2.41 (95\% CI: $1.81-3.23, p=<0.001$ ), and allergy 2.45 (95\% CI: $1.85-3.26, p=<0.001$ ), Table 2.

\section{Discussion}

This study has established that the prevalence of asthma among PLHIV is higher than among those without HIV and that HIV modifies the associations of asthma with tobacco smoking, biomass use, TB, allergy and family history of asthma. The study also shows that the only respiratory symptom more prevalent in PLHIV than without PLHIV is breathlessness. In terms of asthma risk factors the study found that PLHIV have high rates of tobacco smoking and history of TB treatment.

A higher prevalence of asthma among PLHIV has been reported in previous studies in clinic-based studies in high income with low HIV prevalence [6-12]. In 248 HIV infected and 236 HIV uninfected males, the prevalence of wheezing was $54.4 \%$, vs. $21.2 \%, p<0.001$ 
Table 2 Asthma prevalence by HIV and potential confounding factors

\begin{tabular}{|c|c|c|c|c|c|c|}
\hline & $n(\%)$ & Prevalence of asthma \% & Crude PR (95\% CI) & $p$ & Adjusted PR $(95 \% \mathrm{Cl})$ & $p$-value \\
\hline \multicolumn{7}{|l|}{ Characteristic } \\
\hline \multicolumn{7}{|l|}{ HIV status } \\
\hline Infected & $103(5.0)$ & 15.5 & $1.72(1.07-2.75)$ & 0.025 & $1.54(0.94-2.51)$ & 0.085 \\
\hline Uninfected & $1966(95.0)$ & 9.1 & Reference & & Reference & \\
\hline \multicolumn{7}{|l|}{ Gender } \\
\hline Female & $1275(61.6)$ & 9.9 & $1.15(0.87-1.53)$ & 0.319 & $1.24(0.92-1.68)$ & 0.159 \\
\hline Male & $794(38.4)$ & 8.6 & Reference & & Reference & \\
\hline \multicolumn{7}{|l|}{ Smoking } \\
\hline Yes & $168(8.1)$ & 16.7 & $1.91(1.32-2.76)$ & 0.001 & $1.79(1.23-2.60)$ & 0.002 \\
\hline No & $1901(91.9)$ & 8.7 & Reference & & Reference & \\
\hline \multicolumn{7}{|l|}{ Biomass use } \\
\hline Yes & 409 (19.8) & 14.2 & $1.74(1.31-2.32)$ & $<0.001$ & $1.56(1.18-2.07)$ & 0.002 \\
\hline No & $1659(80.2)$ & 8.1 & Reference & & Reference & \\
\hline \multicolumn{7}{|l|}{ TB treatment } \\
\hline Yes & $40(1.9)$ & 22.5 & $2.46(1.36-4.45)$ & 0.003 & $2.20(1.26-3.84)$ & 0.005 \\
\hline No & $2026(98.1)$ & 9.1 & Reference & & Reference & \\
\hline \multicolumn{7}{|c|}{ Family history of asthma } \\
\hline Yes & $235(11.4)$ & 23.8 & $3.16(2.39-4.18)$ & $<0.001$ & $2.41(1.81-3.23)$ & $<0.001$ \\
\hline No & $1832(88.6)$ & 7.5 & Reference & & Reference & \\
\hline \multicolumn{7}{|l|}{ Allergy } \\
\hline Yes & $763(36.9)$ & 16.0 & $2.90(2.20-3.83)$ & $<0.001$ & $2.45(1.85-3.26)$ & $<0.001$ \\
\hline No & $1306(63.1)$ & 5.5 & Reference & & Reference & \\
\hline \multicolumn{7}{|c|}{ TB/HIV (HIV infected and history of TB treatment) } \\
\hline Yes & $10(0.5)$ & 10.0 & $1.07(0.17-6.89)$ & 0.946 & $0.20(0.02-1.66)$ & 0.135 \\
\hline No & $2059(99.5)$ & 9.4 & Reference & & Reference & \\
\hline Age in years ${ }^{\mathrm{a}}$ & & & $2.09(1.52-2.88)$ & $<0.001$ & $1.83(1.30-2.58)$ & 0.001 \\
\hline
\end{tabular}

${ }^{a} \log$ transformed due to skewness, ${ }^{b}$ Adjusted for age, gender, smoking, biomass smoke exposure, allergy, history of TB and family history of asthma, $\mathrm{Cl}$ confidence interval, $T B$ tuberculosis, $P R$ prevalence ratio

[9] while in a study comparing 14,005 HIV infected patients with age matched HIV uninfected controls in Canada, the PR for asthma was 1.31 (95\% CI 1.201.43) [12]. In another study among 223 HIV patients in the USA, the prevalence of doctor diagnosed asthma was 20.6 compared to $8.2 \%$ in the general population [13]. Although after adjusting for other risk factors of asthma such as smoking, biomass smoke, TB, allergy the PR ratio for asthma in PLHIV reduced to 1.54 with a trend $p$-value of 0.085 . The results are however line with the findings from the studies above which increases the possibility that HIV is associated with asthma even in the present study.

We investigated the effect HIV had on the risk of asthma from other asthma risk factors. We found that PLHIV had higher rates of smoking as previously reported $[25,26]$. The prevalence of asthma among tobacco smoking PLHIV was $12.6 \%$ compared to $7.9 \%$ of smokers who were not living with HIV. The finding of high smoking rates among PLHIV in this study has been reported in previous studies [25, 26]. This finding therefore calls for heightened efforts to reduce smoking among PLHIV."

We compared respiratory symptoms between HIV infected and HIV uninfected participants and found that there were no differences except for breathlessness. George et al. found that HIV infected persons had high rates of most respiratory symptoms [21]. We cannot explain why we failed to observe these differences in respiratory symptoms apart from breathlessness. The excess breathlessness in the HIV infected participants might be due to interstitial and diffusion derangements that are so prevalent among HIV infected persons [27-29]. Gingo et al. in a cross-sectional analysis 


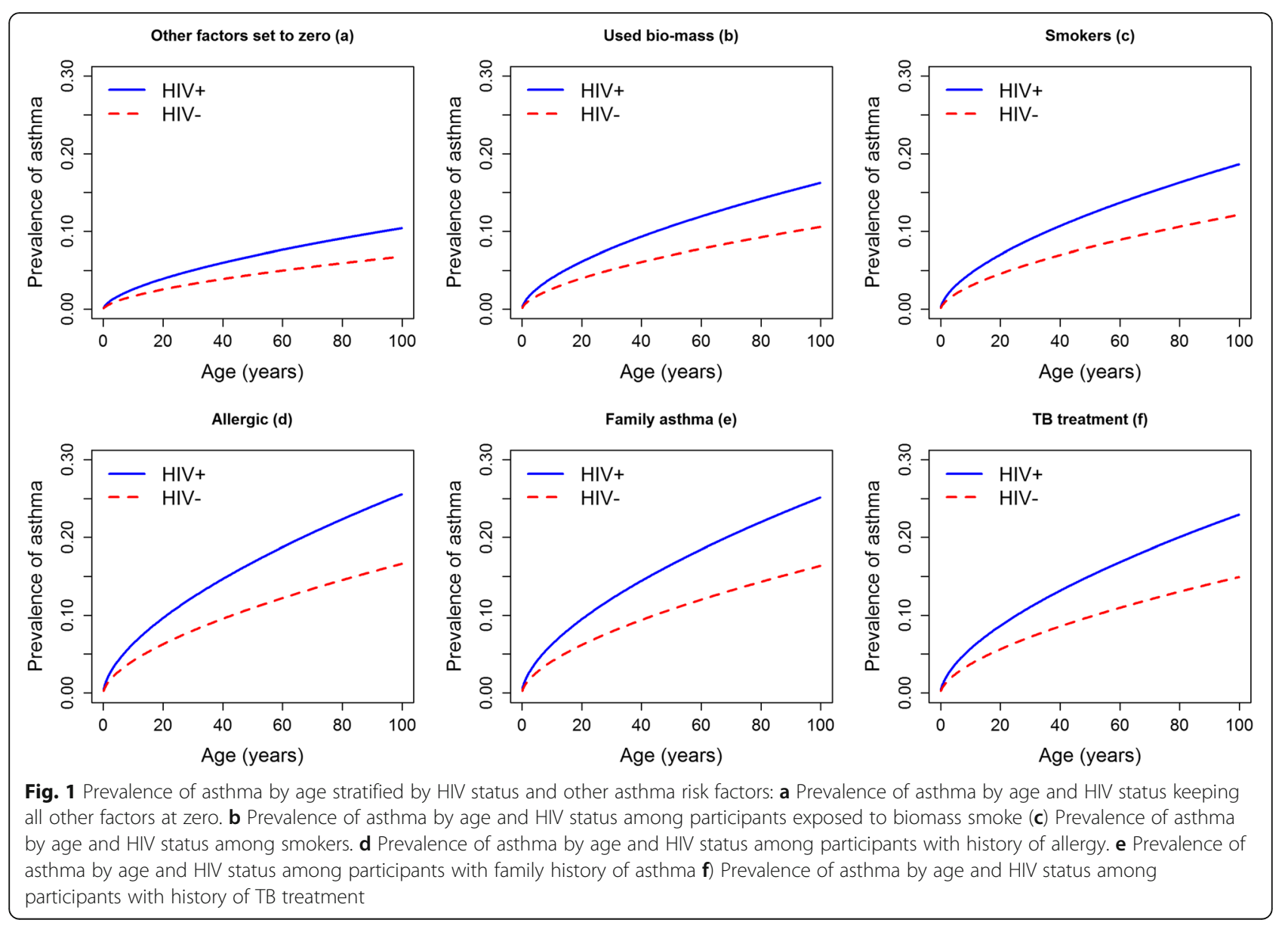

of 158 HIV-infected individuals without acute respiratory symptoms or infection found that 55 (34.8\%) participants had a significantly reduced $\mathrm{DL}_{\mathrm{CO}}(<60 \%$ predicted) [29].

This study had limitations. Most notably the use of self-report to determine HIV infection. Self-report as a means of determining HIV status has been reported to have low sensitivity but high specificity [30, 31]. Among older adults ( $\geq 40$ years) in South Africa, Rohr et al. report a sensitivity of HIV self-report of 51.2\% (95\% CI: 48.2-54.3) and specificity was $99.0 \%$ (95\% CI: 98.7-99.4) [30, 31]. The low sensitivity of self-report may also be present in our study, the self-reported prevalence of HIV in our survey is $3.1 \%$,

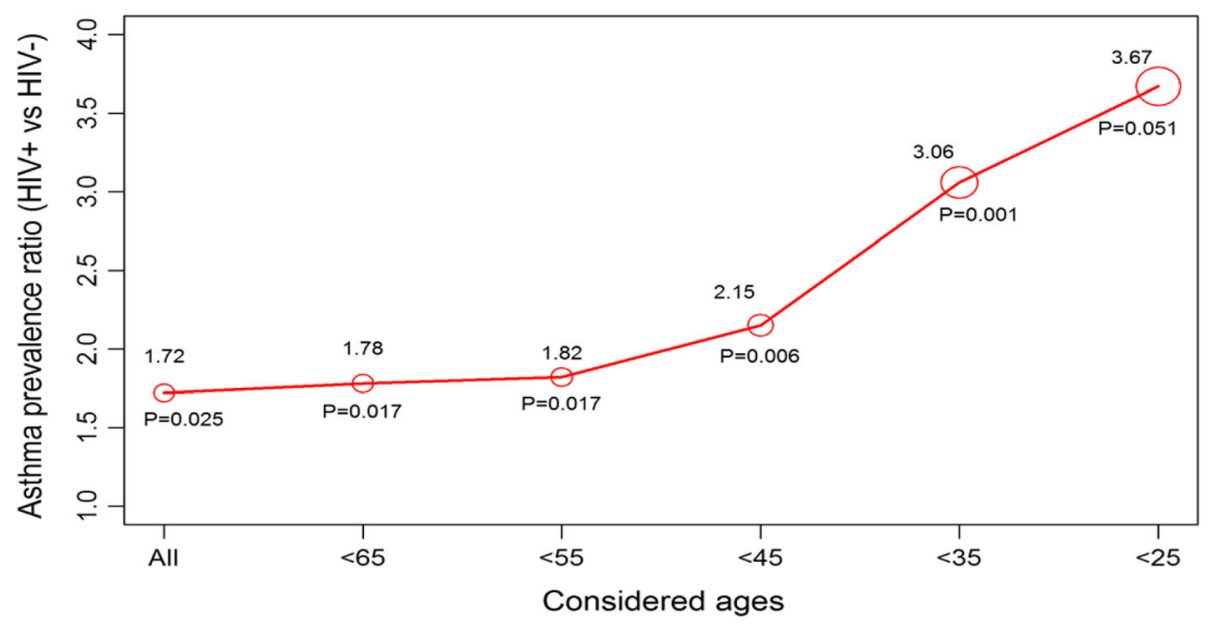

Fig. 2 Asthma prevalence ratios (HIV+ vs HIV-) considering different ages of participants 
Table 3 Participants characteristics by HIV status (known vs. unknown status)

\begin{tabular}{|c|c|c|c|}
\hline & HIV status known ( $N=2069)$ & HIV status unknown $(N=1347)$ & $P$-value \\
\hline \multicolumn{4}{|l|}{ Characteristic } \\
\hline Male gender & $794(38.4)$ & $533(39.6)$ & 0.484 \\
\hline Age groups & & & $<0.001$ \\
\hline$<15$ & $92(4.5)$ & $280(20.8)$ & \\
\hline $15-24$ & $484(23.4)$ & $400(29.7)$ & \\
\hline $25-34$ & $537(26.0)$ & $144(10.7)$ & \\
\hline $35-44$ & $421(20.4)$ & $156(11.6)$ & \\
\hline $45-54$ & $331(16.0)$ & $144(10.7)$ & \\
\hline $55-64$ & $135(6.5)$ & $90(6.7)$ & \\
\hline $65+$ & $69(3.3)$ & $133(9.9)$ & \\
\hline \multicolumn{4}{|l|}{ Respiratory Symptoms } \\
\hline Cough & $427(20.7)$ & $284(21.1)$ & 0.751 \\
\hline Sputum & $147(7.1)$ & $110(8.2)$ & 0.250 \\
\hline Wheezing & $142(6.9)$ & $84(6.2)$ & 0.471 \\
\hline Shortness of breath & $195(9.4)$ & $114(8.5)$ & 0.337 \\
\hline \multicolumn{4}{|c|}{ Risk factors and co-morbid conditions } \\
\hline History of smoking & $168(8.1)$ & $74(5.5)$ & 0.004 \\
\hline Exposure to bio-mass & $409(19.8)$ & $289(21.5)$ & 0.235 \\
\hline Ever been treated for TB & $40(1.9)$ & $10(0.7)$ & 0.005 \\
\hline Allergy & $763(36.9)$ & $433(32.2)$ & 0.005 \\
\hline Family history of asthma & $235(11.4)$ & $142(10.6)$ & 0.455 \\
\hline \multicolumn{4}{|l|}{ Asthma } \\
\hline Positive & $194(9.4)$ & $121(9.0)$ & 0.698 \\
\hline
\end{tabular}

$T B$ tuberculosis

which is much lower than the national prevalence of $6.2 \%$ [4]. We believe that differential classification of HIV by asthma status is unlikely, but if present would likely tend to underestimate the prevalence ratio if patients without HIV are less likely to report HIV status. We performed further analysis on our data comparing demographic characteristics and asthma prevalence between participants with known HIV status and those with unknown HIV status, Table 3. As can be seen in this table the prevalence of asthma among these two groups did not significantly differ.

Another limitation of our study is that asthma was diagnosed based on history or current wheeze, prior physician diagnosis and being currently on asthma medications. However the methods used in this study are the standard methods that are used in most asthma surveys including the ISAAC), ECRHS) and the WHO health survey $[1,22,23]$. We recognise that wheezing could be due to other diseases such as chronic obstructive pulmonary disease (COPD). Therefore, it is possible that some of the participants classified as asthma could have had COPD which is also known to be associated with HIV. We performed sensitivity analysis considering only participants who are younger than 35 years, the age below which the diagnosis of COPD is unlikely and found that the prevalence of asthma in age group was still higher among the HIV infected participants (Fig. 1 left panel) implying that the association between asthma and HIV in this study might be a true one. There are however other conditions that can cause wheezing such as bronchiectasis, heart failure and mechanical airway obstruction $[32,33]$ that we could not exclude although these conditions are deemed to be rare.

Despite the limitations, our findings have several scientific, healthcare and programmatic implications. Firstly, HIV care programs need to build capacity for diagnosis of asthma and its management. At the same time there may be need to test for HIV among asthma patients in high HIV burden settings and to know their ART status and the medications they are taking. Asthma and HIV co-morbidity can be associated with complexities that can arise while managing the two diseases notably drug-drug interactions and increased rates of adverse events as can occur with 


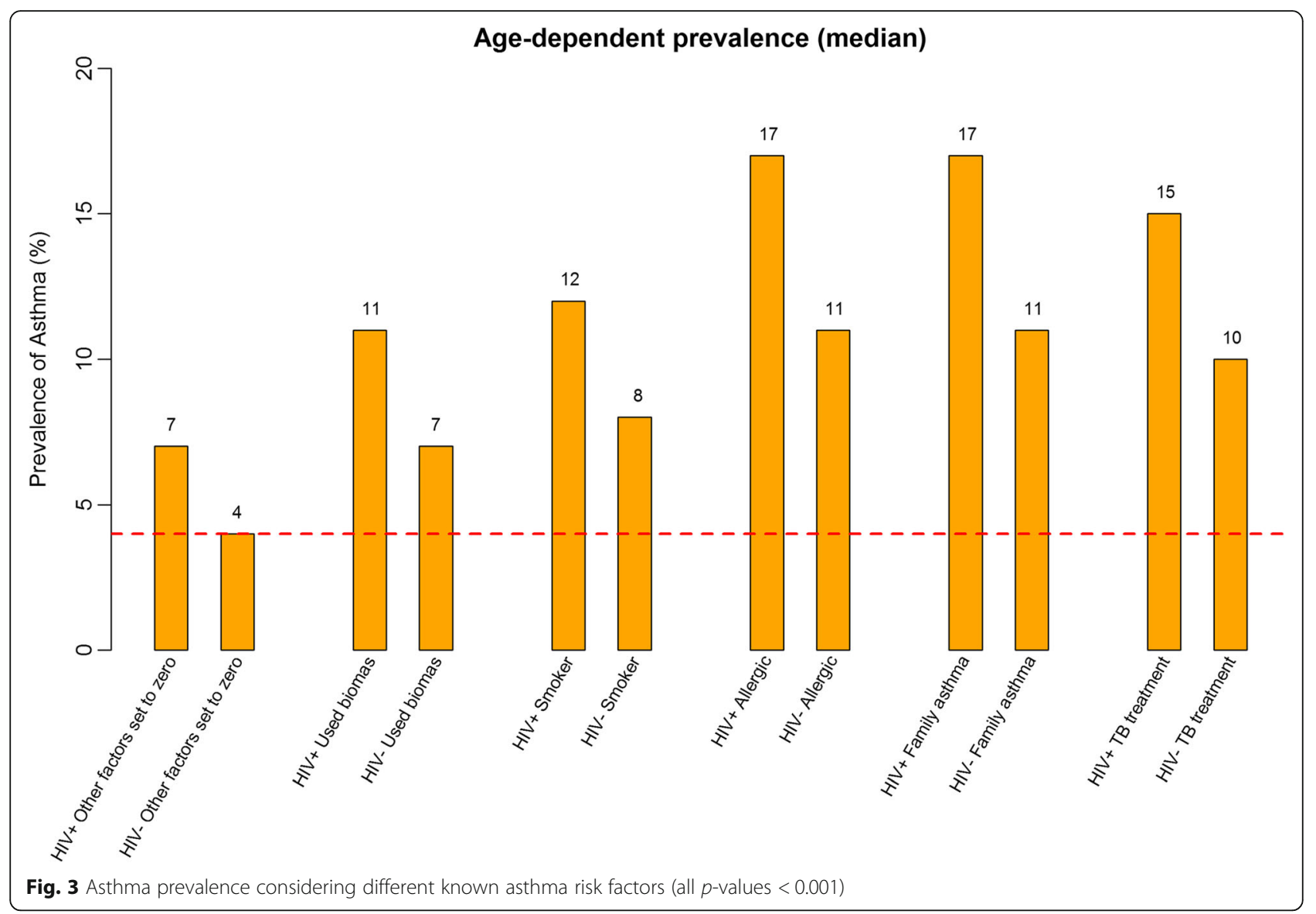

corticosteroids used in the management of asthma. Corticosteroids use in HIV infected persons has been associated with adverse outcomes such as the development of cancers like Kaposi's sarcoma and TB [34-36]. Another key drug-drug interaction to consider is that between protease inhibitors and corticosteroids, which is mediated through the effects of PIs on the cytochrome CYP450 3A4 drug metabolism pathway [37, 38]. This interaction can lead to complications such as Cushing's syndrome, hypertension and poor CD4 cell count recovery [38]. We found that HIV modified the risk of asthma from other risk factors. This calls for vigorous prevention of these risk factors among PLHIV. PLHIV in this study had higher rates of tobacco smoking. This calls for heightened efforts to reduce smoking among PLHIV since they may be more likely to develop tobacco associated lung diseases. In terms of science, our findings call for more research on the impact of HIV on asthma in high HIV burden settings and the mechanistic pathways of the HIV asthma interaction especially in settings with high rates of factors like $\mathrm{TB}$ and biomass smoke exposure. The impact of HIV on asthma prognosis also needs to be studied.

\section{Conclusion}

In conclusion, the prevalence of asthma among PLHIV in this survey is higher than among those without HIV. HIV also modifies the risk of asthma from other asthma risk factors such as tobacco smoking, TB, exposure to biomass, allergy and family history of asthma. PLHIV should be assessed for asthma and asthma patients should undergo HIV testing.

\section{Abbreviations}

ART: Antiretroviral therapy; CD4: Cluster of differentiation 4; Cl: Confidence interval; COPD: Chronic obstructive pulmonary disease; CY: Cytochrome; ECRHS: European community respiratory health survey; HIV: Human immune deficiency virus; HHs: Households; IgE: Immunoglobulin E; IL-4: Interleukin-4; ISAAC: International study of asthma and allergies in children; LMICs: Low and middle-income countries; NCDs: Non-communicable diseases; PLHIV: People living with HIV; PR: Prevalence ratio; TB: Tuberculosis; UNAS: Uganda National asthma survey; USA: Unites States of America; WHO: World Health Organization

\section{Acknowledgements}

The authors thank all study participants and research assistants as well as research managers who were involved in this study. Special thanks go to the data management team headed by Mr. Rogers Sekibira that ensured all data were entered, cleaned and available for analysis in a timely manner.

\section{Funding}

This work was funded by the National Institutes of Health (NIH) (Award No. R24 TW008861) and NCS, UMCG, The Netherlands. 


\section{Availability of data and materials}

The data of the Uganda National Survey is available with the authors.

\section{Authors' contributions}

BJK, TVDM, MRK and CDJ conceived and designed the original survey, supervised data collection and interpreted the data. BJK and LJD conceived the idea of the current analysis of the survey data. BJK and LM analyzed the data. BJK, and WK participated in and supervised data collection. All authors reviewed and contributed to the manuscript writing. All authors read and approved the final manuscript.

\section{Ethics approval and consent to participate}

Ethics approval was obtained from the Mulago Hospital Research and Ethics committee and the Uganda National Council for Science and Technology. Participants provided written informed consent and were free to terminate study participation at any time during the study. For children between the ages of 12-18 years, we obtained their assent and parental/legal guardian consent.

\section{Consent for publication}

Not applicable, this manuscript does not contain any personal data.

\section{Competing interests}

The authors declare that they have no competing interests.

\section{Publisher's Note}

Springer Nature remains neutral with regard to jurisdictional claims in published maps and institutional affiliations.

\begin{abstract}
Author details
${ }^{1}$ Makerere University Lung Institute \& Division of Pulmonary Medicine, Department of Medicine, Makerere University College of Health Sciences, Kampala, Uganda. ${ }^{2}$ Makerere University Lung Institute, Makerere University College of Health Sciences, Kampala, Uganda. ${ }^{3}$ GRIAC-Primary Care, Department of General Practice and Elderly Care, University of Groningen, University Medical Center Groningen (UMCG), Groningen, The Netherlands. ${ }^{4}$ Groningen Research Institute for Asthma COPD (GRIAC), University of Groningen, University Medical Center Groningen (UMCG), Groningen, The Netherlands. ${ }^{5}$ Department of Epidemiology of Microbial Diseases, Yale School of Public Health, and Pulmonary, Critical Care, and Sleep Medicine Section, Yale School of Medicine, New Haven, CT, USA. ${ }^{6}$ Makerere University Lung Institute, Makerere University College of Health Sciences, Kampala, Uganda. ${ }^{7}$ Department of Medicine, Makerere University College of Health Sciences, Kampala, Uganda. ${ }^{8}$ Department of Epidemiology, University of Groningen, Groningen, The Netherlands.
\end{abstract}

Received: 19 July 2018 Accepted: 18 September 2018

\section{Published online: 21 September 2018}

\section{References}

1. To T, Stanojevic S, Moores G, Gershon AS, Bateman ED, Cruz AA, et al. Global asthma prevalence in adults: findings from the cross-sectional world health survey. BMC Public Health. 2012;12(1):204

2. Marais BJ. Childhood tuberculosis: epidemiology and natural history of disease. The Indian Journal of Pediatrics. 2011;78(3):321-7.

3. Adeloye D, Chan KY, Rudan I, Campbell H. An estimate of asthma prevalence in Africa: a systematic analysis. Croatian medical journal. 2013; 54(6):519-31.

4. Ayles H, Muyoyeta M, Du Toit E, Schaap A, Floyd S, Simwinga M, et al. Effect of household and community interventions on the burden of tuberculosis in southern Africa: the ZAMSTAR community-randomised trial. Lancet. 2013; 382(9899):1183-94

5. Morgan BW, Siddharthan T, Grigsby MR, Pollard SL, Kalyesubula R, Wise RA, et al. Asthma and allergic disorders in Uganda: a population-based study across urban and rural settings. In Practice: The Journal of Allergy and Clinical Immunology; 2018

6. Puri A, Gingo M, Morris A. Asthma in HIV-infected population: a review of respiratory symptoms, pulmonary function abnormalities and pathophysiology. Epidemiol. 2014;4:164. https://doi.org/10.4172/2161-1165. 1000164.
7. Wallace JM, Stone GS, Browdy BL, Tashkin DP, Hopewell PC, Rosen MJ, et al. Nonspecific airway hyperresponsiveness in HIV disease. Chest 1997;111(1): 121-127.

8. O'Donnell CR, Bader MB, Zibrak JD, Jensen WA, Rose RM. Abnormal airway function in individuals with the acquired immunodeficiency syndrome. Chest. 1988;94(5):945-8.

9. Poirier CD, Inhaber N, Lalonde RG, Ernst P. Prevalence of bronchial hyperresponsiveness among HIV-infected men. Am J Respir Crit Care Med. 2001;164(4):542-5.

10. Crothers K, Huang L, Goulet JL, Goetz MB, Brown ST, Rodriguez-Barradas $M C$, et al. HIV infection and risk for incident pulmonary diseases in the combination antiretroviral therapy era. Am J Respir Crit Care Med. 2011; 183(3):388-95.

11. Lin RY, Lazarus TS. Asthma and related atopic disorders in outpatients attending an urban HIV clinic. Ann Allergy Asthma Immunol. 1995;74(6):510-5.

12. Kendall CE, Wong J, Taljaard M, Glazier RH, Hogg W, Younger J, et al. A cross-sectional, population-based study measuring comorbidity among people living with HIV in Ontario. BMC Public Health. 2014;14(1):161.

13. Gingo MR, Wenzel SE, Steele C, Kessinger CJ, Lucht L, Lawther T, et al. Asthma diagnosis and airway bronchodilator response in HIV-infected patients. Journal of allergy and clinical immunology. 2012;129(3):708-14. e8.

14. Drummond MB, Kirk GD, Astemborski J, Marshall MM, Mehta SH, McDyer JF, et al. Association between obstructive lung disease and markers of HIV infection in a high-risk cohort. Thorax. 2011:thoraxjnl-2011-200702.

15. Wright DN, Nelson RP Jr, Ledford DK, Fernandez-Caldas E, Trudeau WL, Lockey RF. Serum IgE and human immunodeficiency virus (HIV) infection. J Allergy Clin Immunol. 1990;85(2):445-52.

16. Thuesen B, Husemoen L, Hersoug LG, Pisinger C, Linneberg A. Insulin resistance as a predictor of incident asthma-like symptoms in adults. Clin Exp Allergy. 2009;39(5):700-7.

17. Drummond MB, Merlo CA, Astemborski J, Marshall MM, Kisalu A, Mcdyer JF, et al. The effect of HIV infection on longitudinal lung function decline among injection drug users: a prospective cohort. AIDS (London, England). 2013;27(8):1303.

18. Gingo MR, Morris A. Pathogenesis of HIV and the lung. Current HIV/AIDS Reports. 2013;10(1):42-50.

19. Kidd P. Th1/Th2 balance: the hypothesis, its limitations, and implications for health and disease. Altern Med Rev. 2003:8(3):223-46.

20. Deo SS, Mistry KJ, Kakade AM, Niphadkar PV. Role played by Th2 type cytokines in IgE mediated allergy and asthma. Lung India. 2010;27(2):66.

21. George MP, Kannass M, Huang L, Sciurba FC, Morris A. Respiratory symptoms and airway obstruction in HIV-infected subjects in the HAART era. PLoS One. 2009;4(7):e6328.

22. Asher M, Anderson H, Stewart A, Crane J, Ait-Khaled N, Anabwani G, et al. Worldwide variations in the prevalence of asthma symptoms: the international study of asthma and allergies in childhood (ISAAC). Eur Respir 1998:12(2):315-35

23. Fitzpatrick C, Floyd K. A systematic review of the cost and cost effectiveness of treatment for multidrug-resistant tuberculosis. PharmacoEconomics. 2012 30(1):63-80

24. Coutinho L, Scazufca M, Menezes PR. Methods for estimating prevalence ratios in cross-sectional studies. Revista de saude publica. 2008;42(6):992-8.

25. Mdege ND, Shah S, Ayo-Yusuf OA, Hakim J, Siddiqi K. Tobacco use among people living with HIV: analysis of data from demographic and health surveys from 28 low-income and middle-income countries. Lancet Glob Health. 2017;5(6):e578-e92.

26. Mdodo R, Frazier EL, Dube SR, Mattson CL, Sutton MY, Brooks JT, et al. Cigarette smoking prevalence among adults with HIV compared with the general adult population in the United States: cross-sectional surveys. Ann Intern Med. 2015;162(5):335-44.

27. Doffman SR, Miller RF. Interstitial lung disease in HIV. Clin Chest Med. 2013; 34(2):293-306.

28. Semenzato G, Agostini C. HIV-related interstitial lung disease. Curr Opin Pulm Med. 1995;1(5):383-91.

29. Gingo MR, He J, Wittman C, Fuhrman C, Leader JK, Kessinger C, et al. Contributors to diffusion impairment in HIV-infected persons. Eur Respir J. 2014;43(1):195-203.

30. Rohr JK, Xavier Gómez-Olivé F, Rosenberg M, Manne-Goehler J, Geldsetzer $P$, Wagner RG, et al. Performance of self-reported HIV status in determining true HIV status among older adults in rural South Africa: a validation study. Journal of the International AIDS Society. 2017;20(1). 
31. Validity of data on self-reported hiv status and implications for measurement of arv coverage in malawi. [cited 2018 June 7]; Available from: https://dhsprogram.com/pubs/pdf/WP81/WP81.pdf.

32. Clerf L. Differential diagnosis of wheezing respiration. J Am Geriatr Soc. 1953;1(9):623-6.

33. Lillington GA, Lin H-w. Differential diagnosis of asthma in adults asthma, occult asthma, and Pseudoasthma. Bronchial Asthma: Springer; 1994. p. 171-87.

34. Lee C-H, Kim K, Hyun MK, Jang EJ, Lee NR, Yim J-J. Use of inhaled corticosteroids and the risk of tuberculosis. Thorax. 2013;68(12):1105-13.

35. Brassard P, Suissa S, Kezouh A, Ernst P. Inhaled corticosteroids and risk of tuberculosis in patients with respiratory diseases. Am J Respir Crit Care Med. 2011;183(5):675-8

36. Gill PS, Loureiro C, Bernstein-Singer M, Rarick MU, Sattler F, Levine AM. Clinical effect of glucocorticoids on Kaposi sarcoma related to the acquired immunodeficiency syndrome (AIDS). Ann Intern Med. 1989;1 10(11):937-40.

37. Foisy M, Yakiwchuk E, Chiu I, Singh A. Adrenal suppression and Cushing's syndrome secondary to an interaction between ritonavir and fluticasone: a review of the literature. HIV medicine. 2008;9(6):389-96.

38. Saberi P, Phengrasamy T, Nguyen DP. Inhaled corticosteroid use in HIVpositive individuals taking protease inhibitors: a review of pharmacokinetics, case reports and clinical management. HIV medicine. 2013;14(9):519-29.

Ready to submit your research? Choose BMC and benefit from:

- fast, convenient online submission

- thorough peer review by experienced researchers in your field

- rapid publication on acceptance

- support for research data, including large and complex data types

- gold Open Access which fosters wider collaboration and increased citations

- maximum visibility for your research: over $100 \mathrm{M}$ website views per year

At $\mathrm{BMC}$, research is always in progress.

Learn more biomedcentral.com/submissions 